\title{
Microbial Communities of Ascocarps and Soils in a Natural Habitat of Tuber Indicum
}

\section{Deyuan Wang}

Ludong University

Qiang Xu

Ludong University

\section{Wenjiao Guo}

Ludong University

\section{Fanlin Wu}

Ludong University

\section{Juan Chen}

Chinese Academy of Medical Sciences \& Peking Union Medical College

\section{Peigui Liu}

Chinese Academy of Sciences

Wei Tian ( $\nabla$ tianweixiaoxiao@163.com )

Ludong University https://orcid.org/0000-0003-3705-7599

\section{Peng Qiao}

Shandong Academy of Agricultural Sciences

\section{Research Article}

Keywords: Tuber indicum, bacterial community, fungal community, high-throughput sequencing

Posted Date: November 12th, 2021

DOI: https://doi.org/10.21203/rs.3.rs-1062290/v1

License: (c) (1) This work is licensed under a Creative Commons Attribution 4.0 International License.

Read Full License

Version of Record: A version of this preprint was published at Archives of Microbiology on February 22nd, 2022. See the published version at https://doi.org/10.1007/s00203-022-02763-7. 


\section{Abstract}

Truffles are the fruiting bodies of hypogeous fungi in the genus Tuber. Some truffle species usually grow in an area devoid of vegetation, called brûlé, which knowledge about the microbial composition and structure is still limited. Here, we investigated the bacterial and fungal communities of Tuber indicum ascocarps and soils inside and outside a characteristic brûlé from a poplar plantation with no truffle production history in northeastern China using a high-throughput sequencing approach. A predominance of bacterial phylum Proteobacteria was observed in all samples, with Bacillus among the main genera in the ascocarps, while members of Lysobacter and unidentified Acidobacteria were more abundant in the soil. In addition, Gibberella, Fusarium and Absidia were the dominant fungi in the ascocarps, while Tuber were enriched in the ascocarps and soils inside the brûlé. Soil samples from inside the brûlé had a lower bacterial diversity and a greater fungal diversity than did those from outside the brûlé. Furthermore, some mycorrhization helper bacteria (Rhizobium) and ectomycorrhiza-associated bacteria (Lysobacter) were detected, indicating their potential roles in the complex development of underground fruiting bodies and brûlé formation. These findings may contribute to the protection and cultivation of truffles.

\section{Introduction}

Truffles are the hypogeous fungi belonging to the genus Tuber (Ascomycota) that grow in symbiosis with specific plants and then produce underground fruiting bodies (FBs). The sites where ascocarps are collected usually appear burned (commonly referred to by the French word 'brûlé). T. indicum, known as Chinese black truffle, is one of the most appreciated truffle species with high value in the international market, commercial sales of which are based mainly on wild harvesting in natural habitats. However, increasing demand and overharvesting have resulted in decreased production and habitat destruction of wild truffle globally.

To reverse this trend, many efforts have been focused on modifying soil and growing conditions and using seedlings inoculated with specific truffle species to establish plantations in Europe (Le Tacon et al. 2014; Selosse et al. 2017; Piñuela et al. 2021). With the successful cultivation of T. melanosporum orchards in France, many truffle orchards have been established worldwide, including in European countries (i.e., France, Italy and Spain) and countries on other continents (i.e., Australia, USA and New Zealand) (Hall and Haslam 2012; Reyna and García-Barreda 2014; Bach et al. 2021). At present, over 80\% of the truffles harvested in France are from artificially inoculated orchards (Murat 2015). However, as production yields are often lower than expected, a great deal of effort has focused on improving the productivity and sustainability of truffles and to better understand their life cycle (Rubini et al. 2011; Molinier et al. 2016). Most studies on truffles have focused on ectomycorrhizal (ECM) fungal diversity and nutrient exchange between ascocarps and host trees (Paolocci et al. 2006; Guerin-Laguette et al. 2013; Le Tacon et al. 2015; De la Varga et al. 2017; Deveau et al. 2019). However, a few studies have investigated microbial communities in truffle grounds. For instance, in two studies, the fungal communities inside and outside brûlé in T. melanosporum truffle grounds located in France were compared (Napoli et al. 2010; Mello et al. 2011). The results revealed clear differences in these fungal 
communities and indicated a competitive effect of T. melanosporum on other ECM fungi. Mello et al. (2013) observed that the bacterial communities in the same fields were also affected by truffle brûlé. Among them, Firmicutes, Actinobacteria and Cyanobacteria were more enriched inside the brûlé, while Pseudomonas and Flavobacteriaceae had greater relative abundances outside. These findings have contributed a great deal to an understanding of the truffle brûlé microbial community.

Using high-throughput sequencing technology, the bacterial compositions of ascocarps, ECM and soil in natural habitats have been further analyzed, allowing for speculation as to their potential roles. AntonyBabu et al. (2014) previously observed that the ascocarps of T. melanosporum and T. aestivum provided a habitat for complex bacterial communities that were clearly differentiated from those of the surrounding soil. In addition, the composition of these communities was shown to be dynamic and evolve during the maturation of the ascocarps. Chen et al. (2019) confirmed that more specific bacterial taxa were enriched in the FBs of $T$. indicum than in the soil adhering to ECM. The FBs of $T$. aestivum were also evaluated using sequencing and culture-based methods, resulting in the identification of nine bacterial phyla and six fungal species belonging to three phyla (Perlińska-Lenart et al. 2020). Marjanović et al. (2020) compared the root-associated mycobiomes of three different truffle-producing habitats and showed that ECM fungi were a dominant functional guild. However, these studies focused mainly on bacterial diversity and rarely assessed fungal diversity in natural habitats.

Tuber indicum is distributed mainly in China. In the last decade, our knowledge of the phylogeny (Wang and Liu 2009; Chen et al. 2011; Kinoshita et al. 2018), population genetics (Feng et al. 2016; Qiao et al. 2018) and mycorrhizal synthesis (Geng et al. 2009; Deng et al. 2014; Zhang et al. 2019; 2020) of $T$. indicum has considerably increased. However, only a few studies have assessed the microbial communities of soils in natural habitats of $T$. indicum. The community compositions of bacteria (Deng et al. 2018) and fungi (Fu et al. 2016) of T. indicum collected from southwestern China have been investigated. Chen et al. (2019) studied the bacterial community of ECM, the soil adhering to ECM and ascocarps sampled from nine geographical sites in China and concluded that the microbial communities of ascocarps are influenced by geological locations and soil characteristics. In addition, the quantity of mycorrhizae and the growth of mycorrhizal seedlings were facilitated after being inoculated with Pseudomonas spp., Streptomyces spp. and Variovorax paradoxus on P. armandii (Wang et al. 2015). However, despite these studies, the bacterial and fungal compositions of ascocarps and soils and the connection between them remain poorly characterized. To the best of our knowledge, T. indicum has been poorly studied in northeastern China compared to southwestern China, a better understanding of which will benefit truffle protection and cultivation. Therefore, the main objectives of the present study were to increase our knowledge of the soil bacterial and fungal communities between the inside and outside of the truffle brûle of $T$. indicum growing in association with poplar and to elucidate whether the microbial community of the ascocarp is closely related to the associated soil using high-throughput sequencing.

\section{Material And Methods}

\section{Sampling Site}


The studied habitat was naturally infected, and T. indicum was observed in a plantation in northeastern China. There was no truffle production history based on the experience of the manager. The site is located in Fuyu County, Qiqihar city, Heilongjiang Province, China, lat 4800'14.47" N, long 124³0'35.05" E, altitude $200 \mathrm{~m}$ above sea level (ASL). The plantation, which covers $55 \mathrm{ha}$, is near to natural with respect to the structure of vegetation cover that remained preserved. Chinese poplar (12-15 years old) that were not artificially inoculated were the host trees investigated in the present study. The sampling area was approximately $120 \mathrm{~m}^{2}$ with 18 trees planted (Fig. 1) and ground showed a characteristic brûlé, the only one that we observed in the studied plantation.

\section{Sample Collection}

All samples were collected in autumn. Soil samples were collected from four different points in four directions, with four samples from inside and four from outside of the brûlé (eight soil samples in total). Twenty-two FBs were found and collected from the brûlé. All samples were stored on ice during transport to the laboratory. After removing litter and roots, soil samples from the same direction were air dried, mixed and sieved through a 2-mm sieve to homogenize them as much as possible. The ascocarps were brushed under water to remove soil particles and dried with absorbent paper. Then, four healthy FBs and eight soil samples were processed for microbial community sequencing.

\section{DNA Extraction and Sequencing}

Total genomic DNA was extracted from the gleba (0.05-0.1 g fresh weight excised from the central part of the gleba) of each FB and 0.5-1 g of soil using the CTAB/SDS method (Bruns and Gardes 1993). DNA concentration and purity were monitored on $1 \%$ agarose gels. Based on the concentration, DNA was diluted to $1 \mathrm{ng} / \mu \mathrm{L}$ using sterile water. The $16 \mathrm{~S}$ rRNA V4 region was amplified using primers 515F-806R, and the ITS rDNA region was amplified using the barcoded primers ITS5-1737F and ITS2-2043R. PCR amplification was performed in $30 \mu \mathrm{L}$ reaction volume with $15 \mu \mathrm{L}$ of Phusion ${ }^{\circledR}$ High-Fidelity PCR Master Mix (New England Biolabs), $0.2 \mu \mathrm{M}$ forward and reverse primers, and approximately $10 \mathrm{ng}$ of template DNA. The thermal cycling conditions consisted of initial denaturation at $98^{\circ} \mathrm{C}$ for $1 \mathrm{~min}$ followed by 30 cycles of $98^{\circ} \mathrm{C}$ for $10 \mathrm{~s}, 50^{\circ} \mathrm{C}$ for $30 \mathrm{~s}, 72^{\circ} \mathrm{C}$ for $30 \mathrm{~s}$, with a final extension at $72^{\circ} \mathrm{C}$ for $5 \mathrm{~min}$. PCR products were detected through $2 \%$ agarose gel electrophoresis and staining with SYBR green. The PCR products were purified with a GeneJET ${ }^{\mathrm{TM}}$ Gel Extraction kit (Thermo Scientific). Sequencing libraries were generated using lon Plus Fragment Library Kit 48 rxns (Thermo Scientific) and then the quality was assessed on the Qubit@ 2.0 Fluorometer. At last, the library was sequenced on an lon S5 ${ }^{\mathrm{TM}}$ XL platform (400-600 bp single end) at Tianjin Novogene Bioinformatic Technology Corporation, Tianjin, China.

\section{Statistical Analyses of Microbial Diversity}

Single-end reads was assigned to samples based on their unique barcode and truncated by cutting off the barcode and primer sequence. Then the raw reads were filtered according to the Cutadapt quality control process (Martin 2011), and the chimera sequences were detected using UCHIME algorithm (Edgar et al. 2011) and were removed (Haas et al. 2011). Finally, the clean reads were obtained. The reads were 
assigned to operational taxonomic units (OTUs) at a $97 \%$ sequence similarity threshold by UPARSE software (Edgar et al. 2013). Then each OTU representative sequence was annotated using the Silva Database (Quast et al. 2013) based on the Mothur algorithm, implemented in QIIME (Version 1.9.1). Multiple sequence alignments were conducted using MUSCLE (Edgar 2004) to study the difference of the dominant species in different samples.

Rarefaction curves were used to estimate coverage. Alpha diversity (observed species, Chao1, Shannon, Simpson, ACE) and beta diversity (nonmetric multidimensional scaling; NMDS) were calculated with QIIME (Version 1.7.0) and displayed with the R software environment (Version 2.15.3). Comparisons of bacterial and fungal diversity indices were tested via one-way ANOVA at a threshold level of $P=0.05$ and with Fisher's test. Linear discriminate analysis effect size (LEfSe) analyses were performed for the quantitative analysis of biomarkers among the groups. To measure the distance between samples, we used NMDS analysis to visualize the separation of samples in two dimensions using the vegan package (Oksanen et al. 2019). Permutational multivariate analysis of variance (Anderson 2001) was implemented in the $\mathrm{R}$ package vegan.

\section{Results}

\section{Diversity of Bacterial Communities}

High-throughput sequencing technique was used to detect the microbial communities of ascocarps and soils in the natural habitats of $T$. indicum. The rarefaction curve and Shannon curve indicated that the sequencing depth basically covered the bacterial and fungal species of the samples (Supplementary Fig. S1). A total of 79,262 high-quality sequences were obtained after quality filtering. The sequences were assigned to 3,341 OTUs, 1,775 of which were shared among different samples, as shown in the Venn diagram presented in Fig. 2a. The ascocarps $(T)$ had the greatest number of unique OTUs (262), followed by soil inside the brûlé $(S S, 180)$ and soil outside the brûlé (NSS, 158).

All of the OTUs were classified into 48 phyla, 191 families, and 364 genera. Proteobacteria, Acidobacteria, Firmicutes, Actinobacteria, Bacteroidetes and Planctomycetes were the dominant bacterial phyla in all samples (Supplementary Fig. S2). The ascocarp-associated communities were separated from those of different soil samples (ANOVA, $P<0.05$ ). Firmicutes was significantly more abundant in the ascocarps (29.89\%), while the relative abundances of Acidobacteria and Planctomycetes were significantly greater in the soil samples. Of the 364 genera observed, Bacillus was significantly enriched in the ascocarps (28.26\%) compared with the soils, followed by unidentified Rhizobiaceae accounting for $3.62 \%$ and Bradyrhizobium, with relative abundances of 3.08\% (Fig. 2b). Lysobacter and unidentified Acidobacteria were significantly more abundant in the soils than in the ascocarps, and Lysobacter was twice as abundant inside the brûlé as outside. Moreover, Bacillus simplex (23.21\%), Rhizobium rhizogenes (3.62\%), Bradyrhizobium elkanii $(2.75 \%)$ and B. aryabhattai $(0.95 \%)$ composed a significant portion of the communities in FBs. Burkholderiales bacterium X4 was enriched in the soils, with a relative abundance of $1.65-2.13 \%$ (Supplementary Fig. S3). 
The ascocarps were characterized as having a significantly lower number of observed species and lower diversity index values (except for the Simpson index) than the soil samples (Table 1). Strong similarities between the soils inside and outside the brûlé were observed. LEfSe analysis results revealed significant differences in the bacterial communities among the samples (Fig. 2c, d). Among the different samples, Bacillus, Rhizobiaceae and Bradyrhizobium elkanii were more abundant in the ascocarp samples; Lysobacter and Acidobacteria were more prevalent in the SS samples; and Acidobacteria were more enriched in the NSS samples, followed by Chitinophagaceae, Gaiellales, Myxococcales and Phycisphaerae.

\section{Diversity of Fungal Communities}

A total of 80,160 high-quality sequences were obtained after quality filtering. The sequences were assigned to 1,936 OTUs, 478 of which were shared among the different samples (Fig. 3a). SS had the greatest number of unique OTUs (520), followed by NSS (265) and T (25).

All of the OTUs were classified into eight phyla, 169 families, and 274 genera. Ascomycota was the dominant fungal phylum (24.86-63.59\%) in the different samples, followed by Basidiomycota and Mucoromycota (Supplementary Fig. S4). The relative abundance of Basidiomycota was significantly greater in NSS (36.77\%) than in SS (7.07\%) and the ascocarps $(0.22 \%)$, while that of Mucoromycota was significantly greater in the ascocarps (13.59\%) than in the soils (0.16-1.50\%). Significant differences were also observed on the basis of analyses at the genus and species levels observed (Fig. 3b). For example, the relative abundances of Gibberella (24.27\%), Fusarium (20.08\%), Absidia (13.45\%) and Tuber (9.45\%) in the ascocarps were significantly greater than those in the soils (0.10-2.20\%). Tuber was also prevalent in SS (6.96\%), followed by Mortierella (5.03\%) and Fusarium (1.68\%), while NSS was dominated by Mortierella (6.98\%), Tubulicium (4.68\%), Penicillium (3.16\%) and Fusarium (2.20\%). Absidia glauca (13.45\%), Fusarium solani (13.39\%) and Gibberella intricans (22.72\%) were the dominant fungi in the ascocarps, and Mortierella alpina was enriched in the soils with a relative abundance of $4.83-5.88 \%$ (Supplementary Fig. S5).

The results for the estimated richness indices revealed that the observed species of SS (858 \pm 124$)$ was significantly greater than that of NSS $(698 \pm 46)$, while ascocarps were characterized by a significantly lower number of observed species $(305 \pm 68)$ and lower diversity index values. There was no significant difference in diversity index values between soil samples from inside and outside the brûle except for the Shannon index $(P<0.05)$. LEfSe analysis results indicated differences in fungal communities (Fig. 3c, d). The ascocarps contained significantly more Tuberaceae, Hypocreales, Nectriaceae and Sordariomycetes than the soil samples $(\mathrm{P}<0.05)$, where Fusarium, Gibberella and Tuber were the significantly dominant genera. In contrast, Sordariales, Dothideomycetes and Pleosporales were prevalent in SS, while Thelephorales was enriched in NSS, followed by Mortierella, Trechisporales, Hydnodontaceae and Tubulicium.

\section{Structural Differentiation of Microbial Communities}


The NMDS analysis of the three samples showed that the bacterial and fungal communities in the ascocarps differed and were obviously separated from those of the soils (PERMANOVA, stress $<0.001$ ) (Fig. 4a, b). These results revealed that the bacterial community structures of SS and NSS were similar, while their fungal communities were separated by the sample type.

\section{Discussion}

As fungi that grow underground, truffles are in close contact with soil during their entire life cycle. In the present study, the microbial community of ascocarps and soils inside and outside the brûlé of a $T$. indicum habitat was compared using a high-throughput sequencing method. The plantation we investigated was nearly natural with no artificial inoculation or truffle production history. To protect the plantation, we started a study for which we collected ascocarps and soils from one characteristics brûlé. Our results confirmed earlier data for other Tuber species, where the phyla Proteobacteria, Acidobacteria, Firmicutes, Actinobacteria and Bacteroidetes formed the core component of bacterial communities (Vahdatzadeh et al. 2015; Chen et al. 2019). However, the data revealed significant differences in community composition for some taxa between ascocarps and soil samples. For example, Bacillus, belonging to the phylum Firmicutes, was the dominant bacterial genus detected in the $T$. indicum ascocarp in the present study (28.25\%). It was also observed in the ascocarps of other species, such as $T$. melanosporum (Antony-Babu et al. 2014), T. panzhihuaensis (Wan and Liu 2014) and T. aestivum (Urszula et al. 2020). Bacillus simplex has been reported to be a member of the plant growth-promoting rhizobacteria (Mesanza et al. 2019; Hansen et al. 2020). Interestingly, soil harbors complex communities of bacteria and fungi, which could explain the differences and correlations between them.

Rhizobium and Bradyrhizobium, members of the class Alphaproteobacteria, were the other two important genera detected in the $T$. indicum ascocarps, the presence and predominance of which have been reported in several other truffle species, such as T. borchii (Barbieri et al. 2005), T. magnatum (Barbieri et al. 2007; Monaco et al. 2021) and T. panzhihuaensis (Wan and Liu 2014). Members of these genera are well known for their ability to form symbiotic associations with host plants and for their nitrogen-fixing activities (Barbieri et al. 2005; Hara et al. 2019). Barbieri et al. (2010) assessed the expression of nifH genes from Bradyrhizobium and demonstrated its nitrogen-fixing activity. Rhizobium spp. are mycorrhization helper bacteria that can play a role in ascocarp development. It was previously hypothesized that Bradyrhizobium sp. may have evolved and adapted to the truffle FB niche (Benucci and Bonito 2016). However, inoculation experiments should be carried out to test their potential role during the formation and maturation of the ascocarp.

Compared to bacteria, the diversity and abundance of fungi was much lower in the T. indicum ascocarps. Urszula et al. (2020) proposed that Tuber FBs selectively recruit microorganisms to their gleba, but the mechanisms of this recruitment remain unknown. As expected, Tuber was present in all the ascocarps and soils inside the samples. Some potential pathogenic fungi, such as Fusarium, Absidia, Gibberella and Penicillium, were also present in the ascocarps, among which Absidia and Penicillium were also obtained by in vitro cultivation (Pacioni 2007; Marjanović et al. 2020). In the present study, as ascocarps and soils 
were collected from only one characteristic brûlé, only limited data were obtained. However, additional information could be obtained in the future following the onset of more brûlé in this plantation and studying them.

The use of FBs and soils sampled in the present study allowed us to extract more information on the complex microbial communities of $T$. indicum. Surprisingly, samples from inside the brûlé had a lower bacterial diversity and a greater fungal diversity compared to those collected outside the brûlé, and the analysis revealed a high level of similarity and some differences for a few taxa. For example, soils inside the brûlé showed a greater abundance of Lysobacter and a lower abundance of Actinobacteria than soil outside the brûlé, indicating that specific bacterial populations were selected. In addition, the Basidiomycota ectomycorrhizal fungi (ECM) were dominant in samples from outside the brûlé, while Ascomycota, especially members of the genus Tuber, were more enriched in samples from inside the brûlé, which is in line with the competitive effect of the ectomycorrhizal T. melanosporum on the other ECM fungi (Napoli et al. 2010).

In the present study, the presence of some taxa in the soils, particularly Lysobacter, deserves attention because they were isolated from ECM of $T$. aestivum and have been significantly and positively associated with the ECM (Gryndler and Hršelová 2012). Lysobacter is a gram-negative bacteria that represents a new and rich source for bioactive natural products (Yu et al. 2020). We propose that the presence of this taxon may benefit the symbiosis. In addition, Actinobacteria members have been frequently observed in ECM (Chen et al. 2019), the relative abundance of which was shown to significantly increase from October to January in the soil (Antony-Babu et al. 2014). The relatively high abundance of these bacteria in the soils observed in our present study further indicates a close relationship between Actinobacteria and brûlé formation. However, this taxon was previously shown to be poorly represented or even absent in the ascocarp (Antony-Babu et al. 2013), and our results supported this conclusion.

Some representative taxa were also detected in the soils, similar to that observed in other reports. For instance, members of the phyla Proteobacteria and Acidobacteria were observed in the bulk soils of $T$. melanosporum (Antony-Babu et al. 2013; Deveau et al. 2016) and T. sinoaestivum (Fu et al. 2016). In addition, some fungal taxa, such as Neonectria and Mortierella, were also reported in previous studies of truffles. Neonectria was isolated from the ectomycorrhizosphere of T. indicum (Deng et al. 2012), and Mortierella was observed in soils of T. sinoaestivum (Fu et al. 2016). Members of the taxa Burkholderiales, Penicillium and Tubulicium were absent from other truffle species. This microbial diversity suggests that truffles provide different habitats for their development and maturation.

Our study investigated the bacterial and fungal community of ascocarps and soils inside and outside the brûlé in a naturally infected habitat that produces $T$. indicum. We found that ascocarp-associated microbial communities were significantly different from those of the soils, but there were still some similarities. The bacterial composition matched earlier data for other truffle species, while the limited data showed that the fungal composition was different from that described in other reports. Overall, the results 
of the present study provides information of the coexistence of truffles and microbes and raises additional questions regarding the function of these associated microbes.

\section{Declarations}

\section{Data Availability Statement}

The datasets generated for this study are available at the NCBI database under the GenBank accession number PRJNA669952.

\section{Acknowledgments}

This study was supported by the Project of Shandong Provincial Natural Science Foundation (ZR2020MC001), the National Natural Science Foundation of China (31200248 and 31500016), the Project of Shandong Province Higher Educational Science and Technology Program (J14LE07), and the Key Research and Development Program of Yantai Grant (2019XDHZ089). We thank AJE (https://www.aje.com/) for providing linguistic assistance during the preparation of this manuscript.

\section{References}

1. Anderson MJ (2001) A new method for non-parametric multivariate analysis of variance. Aust Ecol 26:32-46. https:// 10.1111/j.1442-9993.2001.01070.pp.x

2. Antony-Babu S, Deveau A, Van Nostrand JD et al (2014) Black truffle-associated bacterial communities during the development and maturation of Tuber melanosporum ascocarps and putative functional roles. Environm Microbio 16: 2831-2847. https://doi.org/10.1111/14622920.12294

3. Antony-Babu S, Murat C, Deveau A et al (2013) An improved method compatible with metagenomic analyses to extract genomic DNA from soils in Tuber melanosporum orchards. J Appl Microbiol 115:163-170. https://doi.org/10.1111/jam.12205

4. Bach C, Beacco P, Cammaletti P et al (2021) First production of Italian white truffle (Tuber magnatum Pico) ascocarps in an orchard outside its natural range distribution in France. Mycorrhiza. https://doi.org/10.1007/s00572-020-01013-2

5. Barbieri E, Bertini L, Rossi I et al (2005) New evidence for bacterial diversity in the ascoma of the ectomycorrhizal fungus Tuber borchii. FEMS Microbiol Lett 247:23-35. https://doi.org/10.1016/j.femsle.2005.04.027

6. Barbieri E, Guidi C, Bertaux J et al (2007) Occurrence and diversity of bacterial communities in Tuber magnatum during truffle maturation. Environ Microbiol 9:2234-2246. https://doi.org/10.1111/j.1462-2920.2007.01338.x

7. Barbieri E, Ceccaroli P, Saltarelli R et al (2010) New evidence for nitrogen fixation within the Italian white truffle Tuber magnatum. Fungal Biol 114:936-942. 
https://doi.org/10.1016/j.funbio.2010.09.001

8. Benucci GMN, Bonito GM (2016) The truffle microbiome: species and geography effects on bacteria associated with fruiting bodies of hypogeous pezizales. Microb Ecol 72:4-8.

https://doi.org/10.1007/s00248-016-0755-3

9. Bruns TD, Gardes M (1993) Molecular tools for the identification of ectomycorrhizal fungi-taxonspecific oligonucleotide probes for suilloid fungi. Mol Ecol 2:233-242.

https://doi.org/10.1111/j.1365-294X.1993.tb00013.x

10. Chen J, Guo SX, Liu PG (2011) Species recognition and cryptic species in the Tuber indicum complex. PLoS One 6:e14625. https://doi.org/10.1371/journal.pone.0014625

11. Chen J, Li JM, Tang YJ et al (2019) Chinese black truffle associated bacterial communities of Tuber indicum from different geographical regions with nitrogen fixing bioactivity. Front Microbiol 10:2515. https://doi.org/ 10.3389/fmicb.2019.02515

12. De la Varga H, Le Tacon F, Lagoguet $M$ et al (2017) Five years investigation of female and male genotypes in périgord black truffle (Tuber melanosporum Vittad.) revealed contrasted reproduction strategies. Environ Microbiol 19:2604-2615. https://doi.org/10.1111/1462-2920.13735

13. Deng XJ (2012) Study on white Tuber spp. and microbial diversity of Tuber indicum ectomycorrhizosphere and ascomata. Dissertation, Chinese Academy of Sciences

14. Deng XJ, Liu JL, Yan XF et al (2018). Community composition of bacteria associated with ascocarps of Tuber indicum using traditional culture method and Roche 454 high-throughput sequencing. Biodivers Sci 26:1318-1324. https://doi.org/10.17520/biods.2018184

15. Deng XJ, Yu FQ, Liu PG (2014) Contribution to confirmed and synthesized on mycorrhizae of Tuber indicum s.l. with two dominated and subalpine broadleaf trees in Southwestern China. Am J Plant Sci 5:3269-3279. https://doi.org/10.4236/ ajps.2014.521341

16. Deveau A, Antony-Babu S, Le Tacon F et al (2016) Temporal changes of bacterial communities in the Tuber melanosporum ectomycorrhizosphere during ascocarp development. Mycorrhiza 26:389-399. https://doi.org/10.1007/s00572-015-0679-7

17. Deveau A, Clowez P, Petit F et al (2019) New insights into black truffle biology: discovery of the potential connecting structure between a Tuber aestivum ascocarp and its host root. Mycorrhiza 29:219-226. https://doi.org/10.1007/s00572-019-00892-4

18. Edgar RC (2004) MUSCLE: multiple sequence alignment with high accuracy and high throughput. Nucleic acids res 32:1792-1797. https://doi.org/10.1093/nar/gkh340

19. Edgar RC (2013) UPARSE: highly accurate OTU sequences from microbial amplicon reads. Nature methods 10:996-998. https://doi.org/10.1038/NMETH.2604

20. Edgar RC, Haas BJ, Clemente JC et al (2011) Uchime improves sensitivity and speed of chimera detection. Bioinformatics 27:2194-2200. https://doi.org/10.1093/bioinformatics/btr381

21. Feng B, Zhao Q, Xu J et al (2016) Drainage isolation and climate change-driven population expansion shape the genetic structures of Tuber indicum complex in the Hengduan Mountains region. Sci Rep 6:21811. https://doi.org/10.1038/srep21811 
22. Fu Y, Li XL, Li Q et al (2016) Soil microbial communities of three major Chinese truffles in southwest China. Can J Microbiol 62:1-10. https://doi.org/10.1139/cjm-2016-0139

23. Geng LY, Wang XH, Yu FQ et al (2009) Mycorrhizal synthesis of Tuber indicum with two indigenous hosts, Castanea mollissima and Pinus armandii. Mycorrhiza 19:461-467. https://doi.org/10.1007/s00572-009-0247-0

24. Gryndler M, Hršelová H (2012) Isolation of bacteria from ectomycorrhizae of Tuber aestivum Vittad. Acta Mycologica 47:155-160. https://doi.org/10.5586/am.2012.018

25. Guerin-Laguette A, Cummings N, Hesom-Williams N et al (2013) Mycorrhiza analyses in New Zealand truffières reveal frequent but variable persistence of Tuber melanosporum in co-existence with other truffle species. Mycorrhiza 23:87-98. https://doi.org/10.1007/s00572-012-0450-2

26. Haas BJ, Gevers D, Earl AM et al (2011) Chimeric 16S rRNA sequence formation and detection in Sanger and 454-pyrosequenced PCR amplicons. Genome research 21:494-504. https://doi.org/10.1101/gr.112730.110

27. Hall IR, Haslam W (2012) Truffle cultivation in southern hemisphere. In A. Zambonelli and G.M. Bonito (eds), Edible Ectomycorrhizal Mushrooms, Soil Biology 34. https://doi.org/10.1007/978-3642-33823-6_11

28. Hansen V, Bonnichsen L, Nunes I et al (2020) Seed inoculation with penicillium bilaiae and bacillus simplex affects the nutrient status of winter wheat. Biol Fert Soils 56:97-109. https://doi.org/10.1007/s00374-019-01401-7

29. Hara S, Morikawa T, Wasai S et al (2019) Identification of nitrogen-fixing bradyrhizobium associated with roots of field-grown sorghum by metagenome and proteome analyses. Front Microbiol 10:407. https://doi.org/10.3389/fmicb.2019.00407

30. Kinoshita A, Obase K, Yamanaka T (2018) Ectomycorrhizae formed by three Japanese truffle species (Tuber japonicum, T. longispinosum, and T. himalayense) on indigenous oak and pine species. Mycorrhiza 28:679-690. https://doi.org/10.1007/s00572-018-0860-x

31. Le Tacon F, Marçais B, Courvoisier M et al (2014) Climatic variations explain annual fluctuations in French Périgord black truffle wholesale markets but does not explain the decrease in black truffle production over the last 48 years. Mycorrhiza 24:115-125. https://doi.org/10.1007/s00572-0140568-5

32. Le Tacon F, Zeller B, Plain C et al (2015) Study of nitrogen and carbon transfer from soil organic matter to Tuber melanosporum mycorrhizas and ascocarps using ${ }^{15} \mathrm{~N}$ and ${ }^{13} \mathrm{C}$ soil labelling and whole-genome oligoarrays. Plant Soil 395:351-373. https://doi.org/10.1007/s11104-015-2557-7

33. Marjanović Ž, Nawaz A, Stevanović K et al (2020) Root-associated mycobiome differentiate between habitats supporting production of different truffle species in Serbian riparian forests. Microorganisms 8:1331. https://doi.org/10.3390/microorganisms8091331

34. Martin M (2011) Cutadapt removes adapter sequences from high-throughput sequencing reads. Embnet Journal 17:10-12. https://doi.org/10.14806/ej.17.1.200 
35. Mello A, Napoli C, Murat C et al (2011) ITS-1 versus ITS-2 pyrosequencing: a comparison of fungal populations in truffle-grounds. Mycologia 103:1184-1193. https://doi.org/10.3852/11-027

36. Mello A, Ding GC, Piceno YM et al (2013) Truffle brûlés have an impact on the diversity of soil bacterial communities. PLoS One 8:e61945. https://doi.org/10.1371/journal.pone.0061945

37. Mesanza N, Crawford BD, Coulson TJD et al (2019) Colonization of pinus radiata D. Don seedling roots by biocontrol bacteria erwinia billingiae and bacillus simplex. Forests 10:552. https://doi.org/10.3390/f10070552

38. Molinier V, Murat C, Baltensweiler A et al (2016) Fine-scale genetic structure of natural Tuber aestivum sites in southern Germany. Mycorrhiza 26:1-13. https://doi.org/10.1007/s00572-016-0719y

39. Monaco P, Bucci A, Naclerio G, Mello A (2021) Heterogeneity of the white truffle Tuber magnatum in a limited geographic area of Central-Southern Italy. Environ Microbiol Rep. https://doi.org/10.1111/1758-2229.12956

40. Murat C (2015) Forty years of inoculating seedlings with truffle fungi: past and future perspectives. Mycorrhiza 25:77-81. https://doi.org/10.1007/s00572-014-0593-4

41. Napoli C, Mello A, Borra A et al (2010) Tuber melanosporum, when dominant, affects fungal dynamics in truffle grounds. New Phytol 185:237-47. https://doi.org/10.1111/j.14698137.2009.03053.x

42. Oksanen J, Blanchet FG, Friendly F et al (2019) Vegan: Community Ecology Package. R Package Version 2.3-6. http://CRAN.R project.org/package=vegan

43. Pacioni $G$, Leonardi $M$, Aimola $P$ et al (2007) Isolation and characterization of some mycelia inhabiting Tuber ascomata. Mycol Res 111:1450-1460. https://doi.org/10.1016/j.mycre s.2007.08.016

44. Paolocci F, Rubini A, Riccioni C et al (2006) Reevaluation of the life cycle of Tuber magnatum. Appl Environ Microbiol 72:2390-2393. https://doi.org/10.1128/AEM.72.4.2390-2393.2006

45. Perlińska-Lenart U, Pisyk S, Gryz E et al (2020) Identification of bacteria and fungi inhabiting fruiting bodies of burgundy truffle (Tuber aestivum vittad.). Arch Microbiol 202:1-12. https://doi.org/10.1007/s00203-020-02002-x

46. Piñuela Y, Alday JG., Oliach D et al (2021) White mulch and irrigation increase black truffle soil mycelium when competing with summer truffle in young truffle orchards. Mycorrhiza. https://doi.org/10.1007/s00572-020-01018-x

47. Qiao P, Tian W, Liu P et al (2018) Phylogeography and population genetic analyses reveal the speciation of the Tuber indicum complex. Fungal Genet Biol 113:1423. https://doi.org/10.1016/j.fgb.2018.02.001

48. Quast C, Pruesse E, Yilmaz P et al (2013) The SILVA ribosomal RNA gene database project: improved data processing and web-based tools. Nucl Acids Res D590-D596. https://doi.org/10.1093/nar/gks1219 
49. Reyna S, García-Barreda S (2014) Black truffle cultivation: A global reality. Forest Syst 23:317-328. https://doi.org/10.5424/fs/2014232-04771

50. Rubini A, Belfiori B, Riccioni C et al (2011) Tuber melanosporum: mating type distribution in a natural plantation and dynamics of strains of different mating types on the roots of nursery-inoculated host plants. New Phytol 189:723-735. https://doi.org/10.1111/j.1469-8137.2010. 03493.x

51. Selosse MA, Schneider-Maunoury L, Taschen E, Rousset F et al (2017) Black truffle, a hermaphrodite with forced unisexual behaviour. Trends Microbiol 25:784-787.

https://doi.org/10.1016/j.tim.2017.05.010

52. Urszula P, Pisyk S, Gryz E et al (2020) Identification of bacteria and fungi inhabiting fruiting bodies of burgundy truffle (Tuber aestivum Vittad.). Arch Microbiol 202:2727-

2738. https://doi.org/10.1007/s00203-020-02002-x

53. Vahdatzadeh M, Deveau A, Splivallo R (2015) The role of the microbiome of truffles in aroma formation: a meta-analysis approach. Appl Environ Microbiol 81:6946-6952.

https://doi.org/10.1128/AEM.01098-15

54. Wan SP, Liu PG (2014) Diversity of culturable bacteria associated with ascocarps of a Chinese white truffle, Tuber panzhihuanense (Ascomycota). Plant Divers Resour 36: 29-36. https://doi.org/10.7677/ynzwyj20141301

55. Wang R, Liu PG, Wan SP et al (2015) Study on mycorrhization helper bacteria (MHB) of Tuber indicum. Microbiology China 42:2366-2376. https://doi.org/10.13344/j.microbiol.china.150162

56. Wang Y, Liu PG (2009) Achievements and Challenges of Research on Truffles in China. Plant Diversity 31:1-3. https://doi.org/

57. Yu LJ, Du FY, Chen XS et al (2020). Identification of the Biosynthetic Gene Cluster for the anti-MRSA Lysocins through Gene Cluster Activation Using Strong Promoters of Housekeeping Genes and Production of New Analogs in Lysobacter sp. 3655. ACS Synth. Biol. 9:1989-1997. https://doi.org/10.1021/acssynbio.0c00067

58. Zhang XP, Li XL, Wu CG et al (2019) Exogenous Nitric Oxide and Phosphorus Stress Affect the Mycorrhization, Plant Growth, and Associated Microbes of Carya illinoinensis Seedlings Colonized by Tuber indicum. Front Microbiol 10:2634. https://doi.org/10.3389/fmicb.2019.02634

59. Zhang XP, Li XL, Ye L et al (2020) Colonization by Tuber melanosporum and Tuber indicum affects the growth of Pinus armandii and $p h o D$ alkaline phosphatase encoding bacterial community in the rhizosphere. Microbiol Res 239:126520. https://doi.org/10.1016/j.micres.2020.126520

\section{Tables}

Table 1. Community richness and diversity indices of bacteria and fungi in Tuber indicum Fruiting bodies and soils inside and outside the brûlé 


\begin{tabular}{lllll} 
Sample & & T & SS & NSS \\
\hline Bacterial indices & Observed species & 1269 & 1936 & 1936 \\
\hline & Chao1 index & 1446 & 2119 & 2062 \\
\hline & ACE index & 1421 & 2134 & 2117 \\
\hline & Shannon index & 6.51 & 8.91 & 8.98 \\
\hline Fungal indices & Simpson index & 0.88 & 0.99 & 1.00 \\
\hline & Observed species & - & 823 & 655 \\
\hline & Chao1 index & - & 953 & 712 \\
\hline & ACE index & - & 903 & 716 \\
\hline & Shannon index & - & 5.87 & 5.19 \\
\hline & Simpson index & - & 0.94 & 0.91
\end{tabular}

T, Fruiting bodies of $T$. indicum; SS, soil inside the brûlé; NSS, soil outside the brûlé.

Figures 


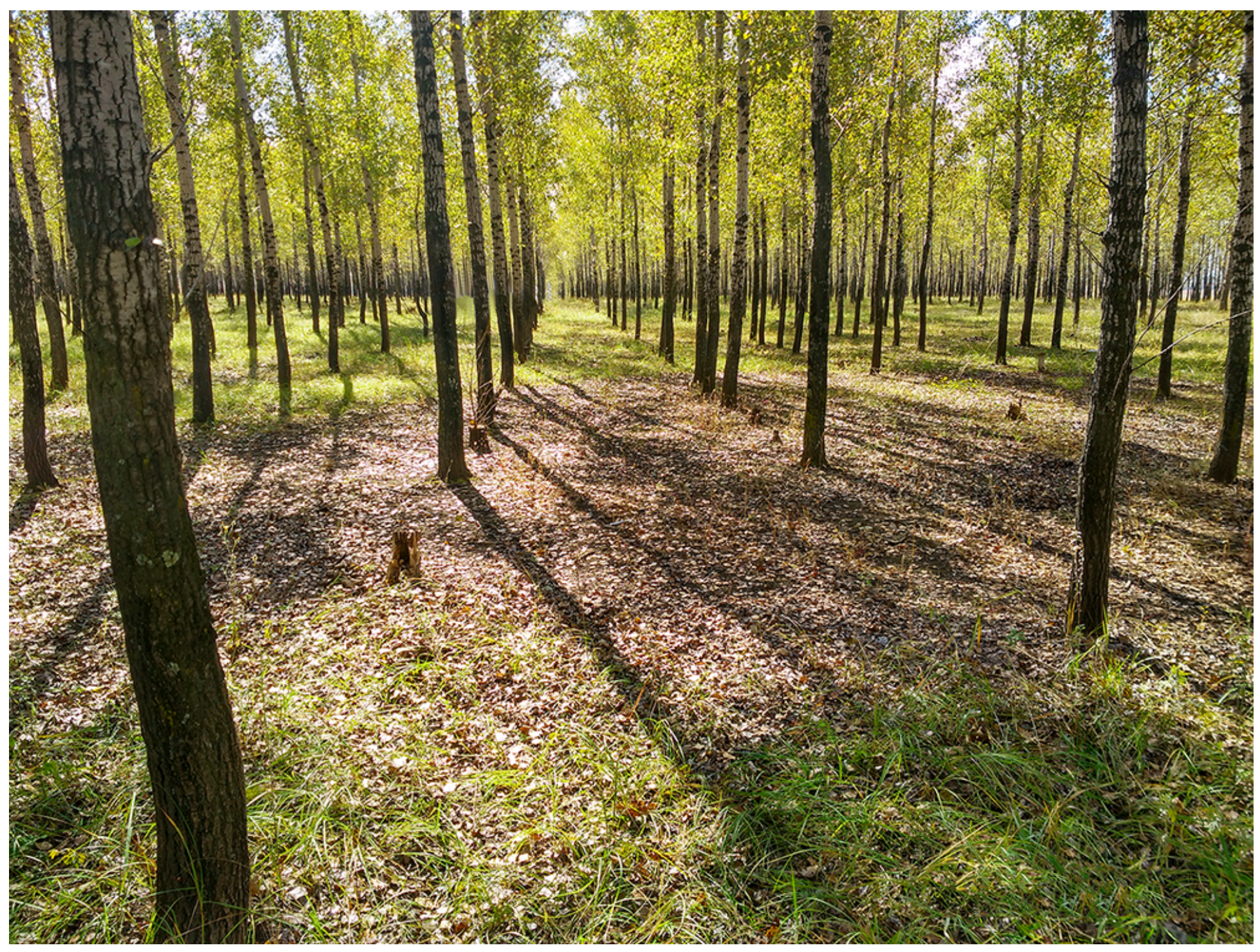

Figure 1

Natural T. indicum production areas in a Chinese white poplar forest in Qiqihar city, Heilongjiang Province, China. The 'brûle' area is devoid of vegetation and nearly circular 
A

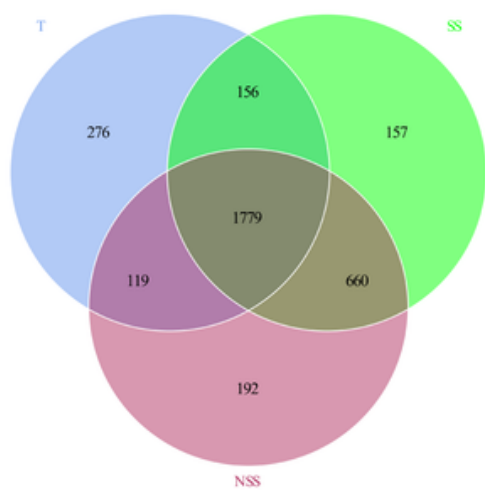

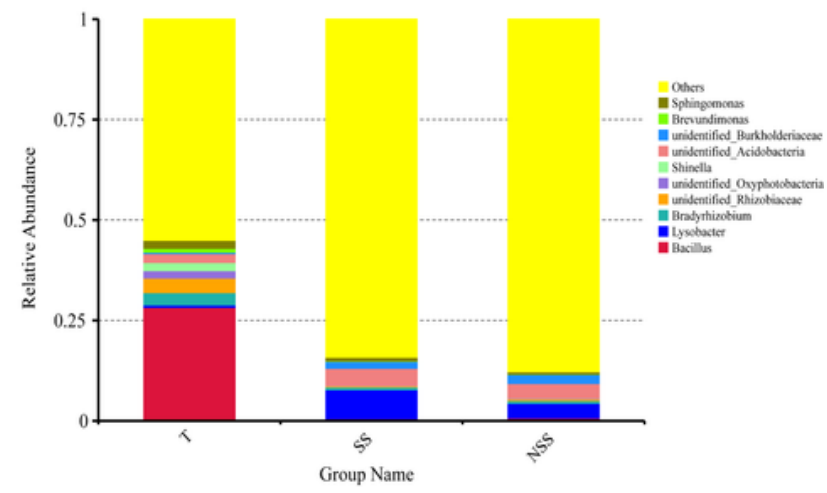

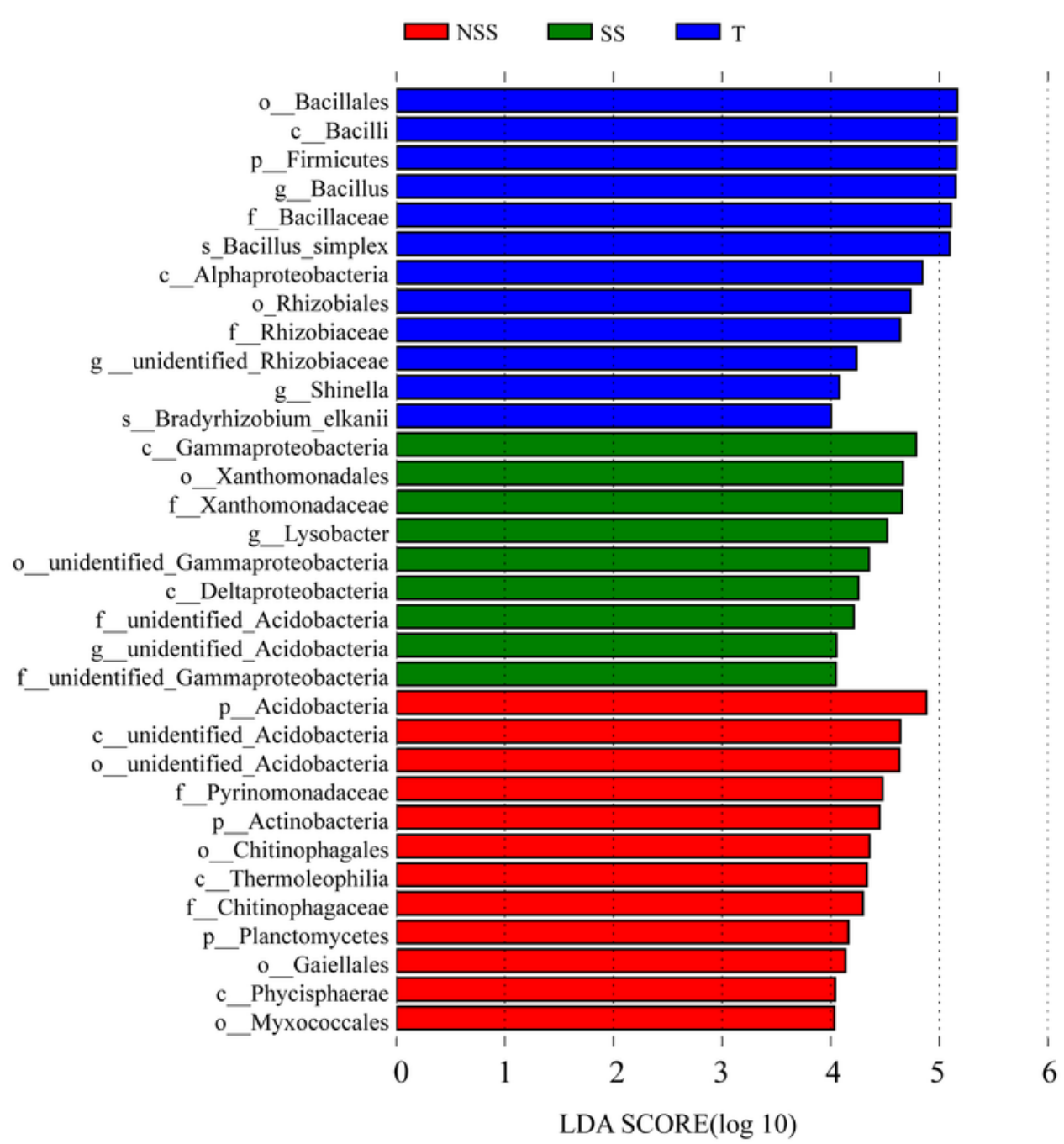

Figure 2

(a) Venn diagram showing the number of bacterial OTUs that are unique or shared by fruiting bodies of T. indicum and soils inside and outside the brûlé. (b) Taxonomic composition of the T, SS and NSS bacterial communities at the genus level. (c) Differentially abundant genera in different samples inferred by the LEfSe algorithm $(P<0.05$, LDA score $>4)$. (d) Cladogram based on the LEfSe analysis showing significant 
differences in the abundances of bacterial taxa in different groups. T, fruiting bodies of T. indicum; SS, soils inside the brûlé; NSS, soils outside the brûlé; Qthers, unclassified taxa.

A

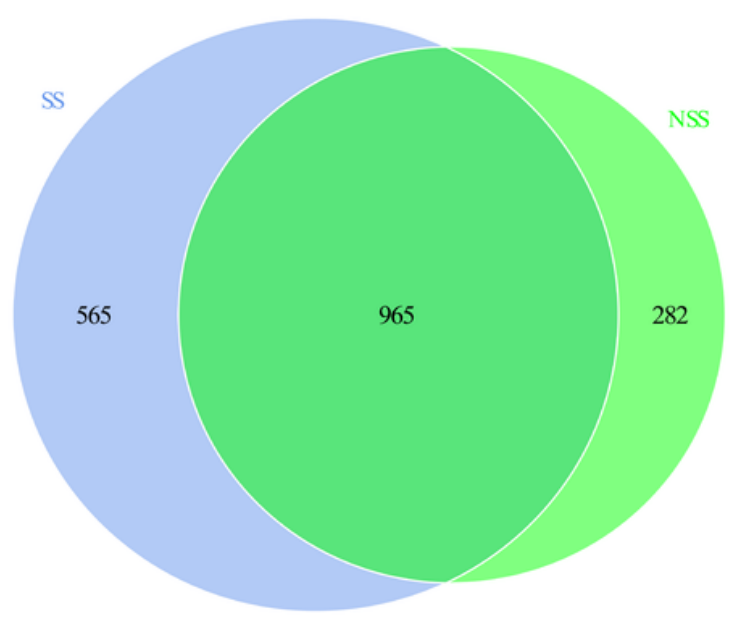

B

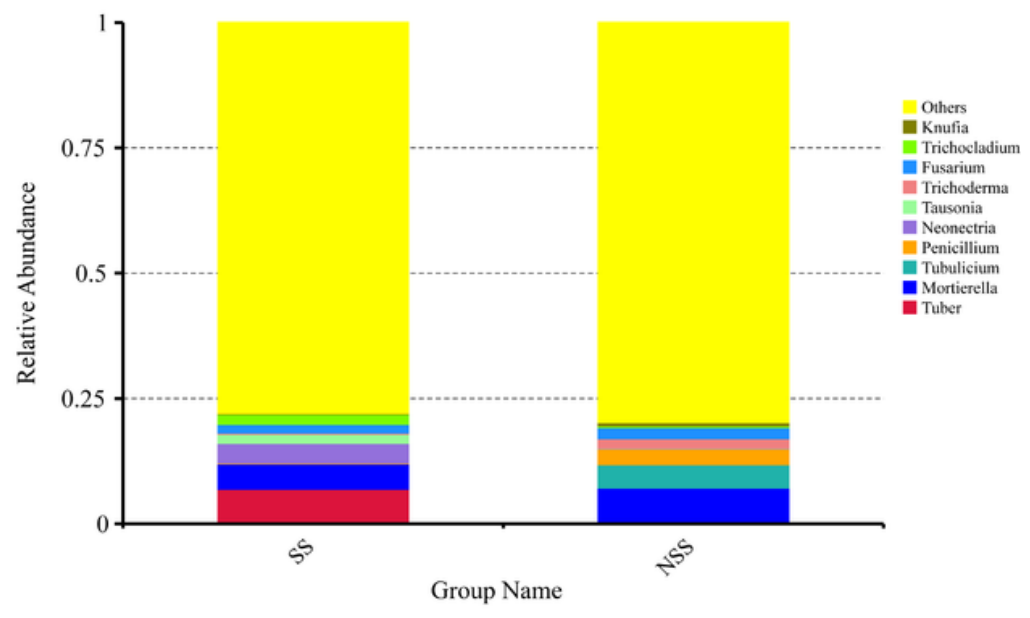

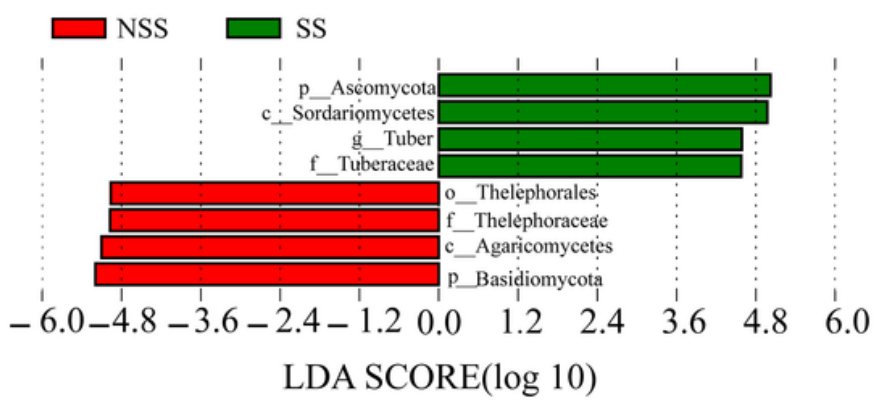

Figure 3

(a) Venn diagram showing the number of fungal OTUs that are unique or shared by fruiting bodies of T. indicum and soils inside and outside the brûlé. (b) Taxonomic composition of T, SS and NSS fungal communities at the genus level. (c) Differentially abundant genera in different samples inferred by the LEfSe algorithm ( $P<0.05$, LDA score $>4)$. (d) Cladogram based on the LEfSe analysis showing significant differences in the abundances of fungal taxa in different groups. T, fruiting bodies of T. indicum; SS, soils inside the brûlé; NSS, soils outside the brûlé; Qthers, unclassified taxa. 
A

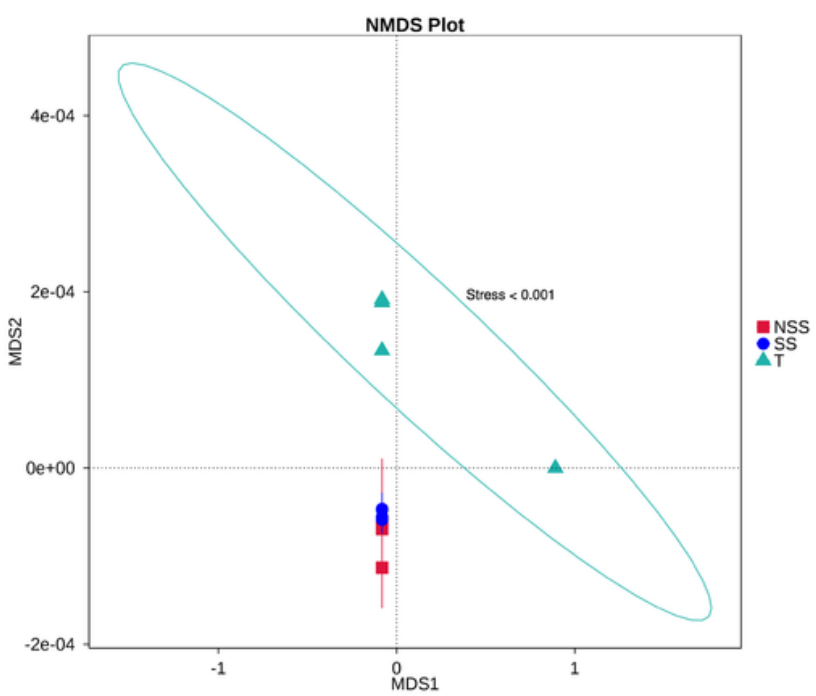

B

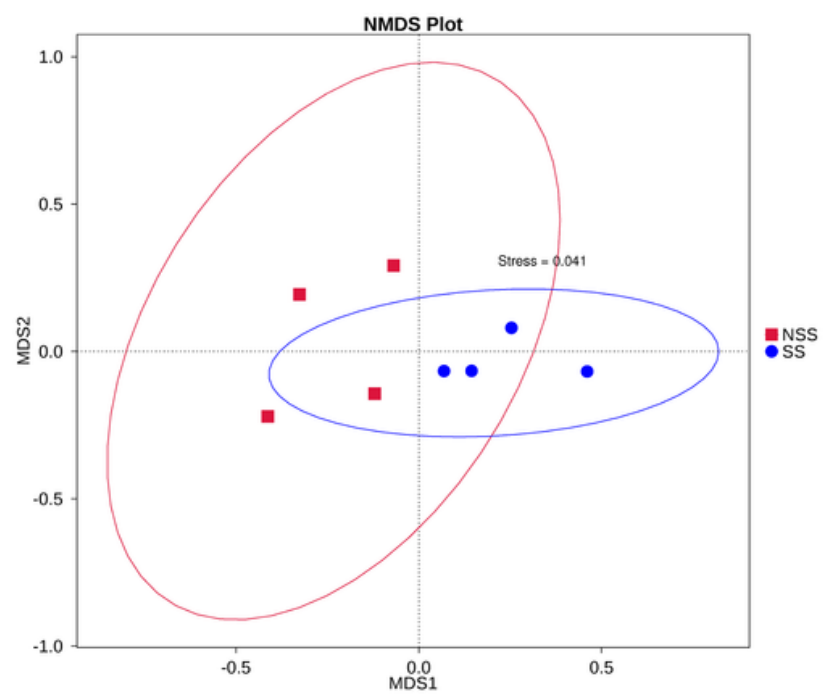

\section{Figure 4}

Nonmetric multidimensional scaling (NMDS) analysis of (a) bacterial and (b) fungal communities in different samples. T, fruiting bodies of T. indicum; SS, soils inside the brûlé; NSS, soils outside the brûlé; Qthers, unclassified taxa.

\section{Supplementary Files}

This is a list of supplementary files associated with this preprint. Click to download.

- SupplementaryMaterial.docx 